\title{
An Analysis of Aluminium Oxide and Silicon Dioxide as a Dielectric on Nano Structured Bottom Gate Bottom Contact Organic Thin Film Transistor Based Sensor
}

\author{
Dr. Subhadra Rajpoot
}

Department of Applied Science, Amity University, Greater Noida (Uttar Pradesh) India.

\section{To Cite this Article}

Dr. Subhadra Rajpoot, "An Analysis of Aluminium Oxide and Silicon Dioxide as a Dielectric on Nano Structured Bottom Gate Bottom Contact Organic Thin Film Transistor Based Sensor", International Journal for Modern Trends in Science and Technology, 6(8): 31-35, 2020.

Article Info

Received on 02-June-2020, Revised on 26-June-2020, Accepted on 23-July-2020, Published on 28-July-2020.

\section{ABSTRACT}

A Nano-structuredflexible bottom gate bottom contact (BGBC) organic thin film transistor based pentacenesensor was utilisedto compare between the two frequently used dielectric material i.ealuminiumoxide $\left(\mathrm{Al}_{2} \mathrm{O}_{3}\right)$ and silicon dioxide $\left(\mathrm{SiO}_{2}\right)$. The organic sensor served as an excellent gas sensor which was visualised through the simulation result in the form of variation between itsmax. and min. drain current and Ion / Ioffratio. The Ion / Ioffratio in the case ofaluminiumoxidewas found to be greater as compared to silicon dioxide whereas the minimum drain current was greater in the case of silicon dioxide and vice versa for the maximum drain current. On comparing the sensitivity of the device, which is the ratio of difference between min. drain current in the presence of any toxic gas and min. drain current in the absence of air to the min. drain current in the absence of air with respect tothe twodifferent electrodes wasfound to be 0.0314 for aluminiumoxide and 0.02964 for silicon dioxide. Hence, aluminiumoxide taking upper hand in sensitivity

Keywords- Bottom gate bottom contact, Aluminium oxide, Silicon oxide, sensitivity Organic thin film transistor

\section{INTRODUCTION}

In the recent years organic electronics has faced a boom due to its compelling application in electronic industry. Organic For application in polymer integrated circuit thin field effect transistor have been fabricated. The advantages have been exposed in the areas as like pixel switches, drivers for displays and integrated circuits. The latest appearing area being that of sensors. Semiconductors as like oligomericandpolymeric fabrication, possess less weight and provide very largesurface area hence have dethroned the traditional gas sensing technologies. Malleable devices have become one of the most influential automation for the latergroup of electronic which will be linked on any other surface. When the comprehended circuit is analysed, it is found that there is a lot more difficulty caused due to integration of various organic and inorganic material on a flexible substrate. Nonetheless, to recogniseahighspeed, high sensitive, low costand a low power consumption device, organic thin field effect are integrated with 
various organic and inorganic dielectric as well as substratematerial.

Compelling amounts of gas sensor with high sensing capability have been reported till date. In the following paper an elaborate comparison would be made of bottom gate bottom contact (BGBC) based organic thin film transistor along different inorganic dielectric material comprising of aluminium oxide and Silicon dioxide. Fig 1 depicts the molecular arrangement of the two dielectric material to be analysed. Both the materials have caused a compelling upsurge in the electronic industry. A comparative enquiry is made on drain voltage $(\mathrm{Vd})$ versus drain current (Id) and gate voltage(Vg) versus drain current(Id) , to confront the device sensitivity and selectivity. A graphical correlation was contrived for the two cases. In the study, the scheduled organic thin film transistor is operated in accumulation mode by employing a negative gate bias voltage, dominating to a grounded source electrode and a negatively biased drain electrode .The device was analysed at room temperature of $300 \mathrm{~K}$ with the two specified dielectric material.[2]

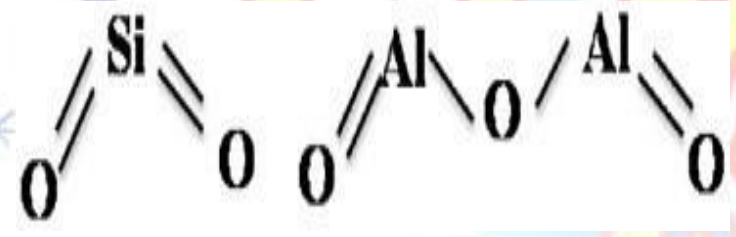

(a)

\begin{tabular}{|c|c|c|}
\hline Property & $\begin{array}{c}\text { Aluminium } \\
\text { oxide } \mathbf{( A l}_{\mathbf{2}} \mathbf{O}_{\mathbf{3}} \text { ) }\end{array}$ & $\begin{array}{c}\text { Silicon } \\
\text { Dioxide(SiO) }\end{array}$ \\
\hline Crystal Structure & Amorphous & Amorphous \\
\hline Dielectric Constant & 9 & 3.9 \\
\hline Band Gap & 8.7 & 8.9 \\
\hline Dielectric Strength & 14.6 & 10 \\
\hline Specific Heat & 0.21 & 1.0 \\
\hline
\end{tabular}

(b)

Fig1-(a)Moleculararrangementand(b)Electricala ndThermal properties of $\mathrm{SiO} 2$ and $\mathrm{Al} 2 \mathrm{O} 3$

\section{EXPERIMENT}

A commendable organic thin film transistor arrangement was utilisedwith the bottom gate bottom contact (BGBC) type configuration with a substrate $\mathrm{m}$ up of PEDOT.PSS( poly(3,4ethylenedioxythiophene) polystyrenesulfonate), that acts as an active gate material with ohmiccontact.. Drain and source electrodes are assembled by depositing gold film on top of gate dielectric with photolithographically characterisedchannel [2].

Pentacenefilm was deposited by thermal evaporation on dielectric. As OTFTs usually operate in accumulation region and pentacenepossess p-channel behaviour, gate and drain are consequently negative bias and source is grounded in experiment.

The dielectric is consequently altered between aluminiumoxide and silicon dioxide to check on the various electrical and electronic parameters over different permittivity of gasses at a fixed temperature of $300 \mathrm{~K}$ i.e. room temperature. Fig 2 depicts bottom gate bottom contact organic thin field transistor based on the two dielectric i.e. Aluminiumoxide and silicon dioxide to beexamined.[2]

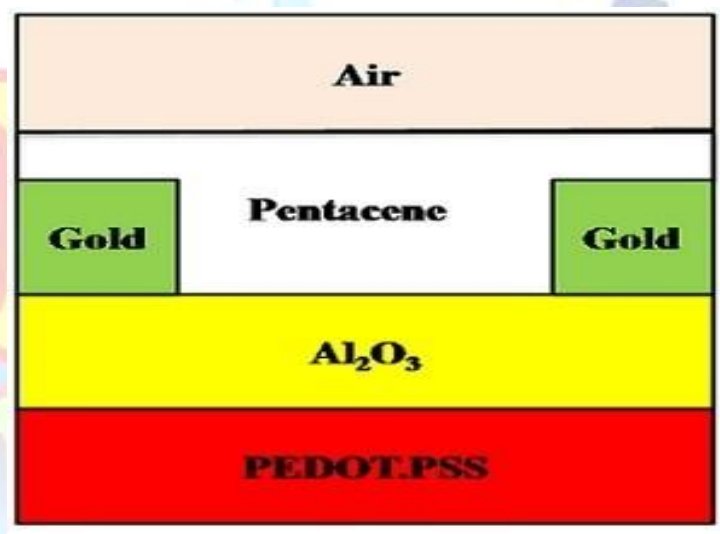

(a)

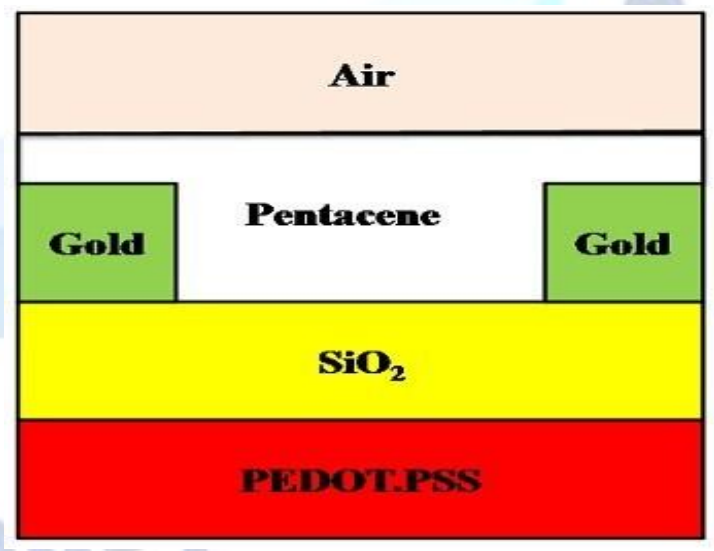

(b)

Fig 2- (a) An aluminium oxide based bottom gate bottom contact OTFT (b) Asilicondioxide based bottom gate bottom contact OTFT

\section{RESULTS AND Disdussion}

A voltage to current characteristic was analysedat a room temperature of $300 \mathrm{~K}$. Linear variations was drawn with respect to drain 
current and gate voltage and drain current and drain voltage in a saturation region at drain source voltage to be - 3V. The permittivity's of gasses were changed to check the device for the presence of different toxic gasses in the given environment..The dielectric material of the device was altered to check on the two conditions. Large leakage current was attributed along source and drain junction although when device is in the off state condition due to its structural characteristic [2].

The electrical and electronics parameters of bottom gate bottom contact (BGBC) organic thin film transistor (OTFT) was studied through the simulation setup using Silvaco 2- D numerical simulator. The materials not previously defined in the simulator are specified with all the parameters. Physical modelling, structural dimension and mess specification and material parameters as well as operational bias condition contribute to the complete simulation process in the simulator. All the layers of the device constitute of organic material and hence the device was simulated keeping all the parameters fixed except different permittivity for various toxic gasses[7].

On the basis of the result from the simulation sensitivity of the device with respect to both the dielectric was compared which was the measure of the ratio between the difference of the minimum drain current in the presence of toxic gas and the minimum drain current in the absence of any toxic gas to the minimum drain current in the absence of any toxic gas.

\section{Case 1- Aluminium Oxide as a dielectric}

The device was analysed with aluminium oxide $\left(\mathrm{Al}_{2} \mathrm{O}_{3}\right)$ as a dielectric material. Table 1 shows the deflection in min. and max. Drain current and Ion / Ioff ratio whereas Fig 3 depicts the graphical representation between the Gate voltage versus drain current as well as Drain voltage versus drain current characteristic of sensor. The sensitivity of the arrangement was calculated as 0.0314 .

\begin{tabular}{|l|l|l|l|l|}
\hline \multicolumn{1}{|c|}{ Gas } & Permittivity & \multicolumn{1}{|c|}{$\begin{array}{c}\text { Min. Drain } \\
\text { Current (Idmin) }\end{array}$} & $\begin{array}{c}\text { Max. Drain } \\
\text { Current(Idmax) }\end{array}$ & Ion/Ioff \\
\hline $\begin{array}{l}\text { Sulphur } \\
\text { Dioxide }\end{array}$ & 82 & 5.75062 & 6.63391 & 88.0709 \\
\hline EthylAlcohol & 78 & 5.74339 & 6.63382 & 88.0983 \\
\hline Ammonia & 71 & 5.73052 & 6.63366 & 88.1468 \\
\hline Oxygen & 4.94 & 5.58827 & 6.63211 & 88.6482 \\
\hline Nitrogen & 2.72 & 5.58243 & 6.63206 & 88.6666 \\
\hline
\end{tabular}

Table 1 - Variation of min. and max. drain current and Ion/Ioff due to different gasses
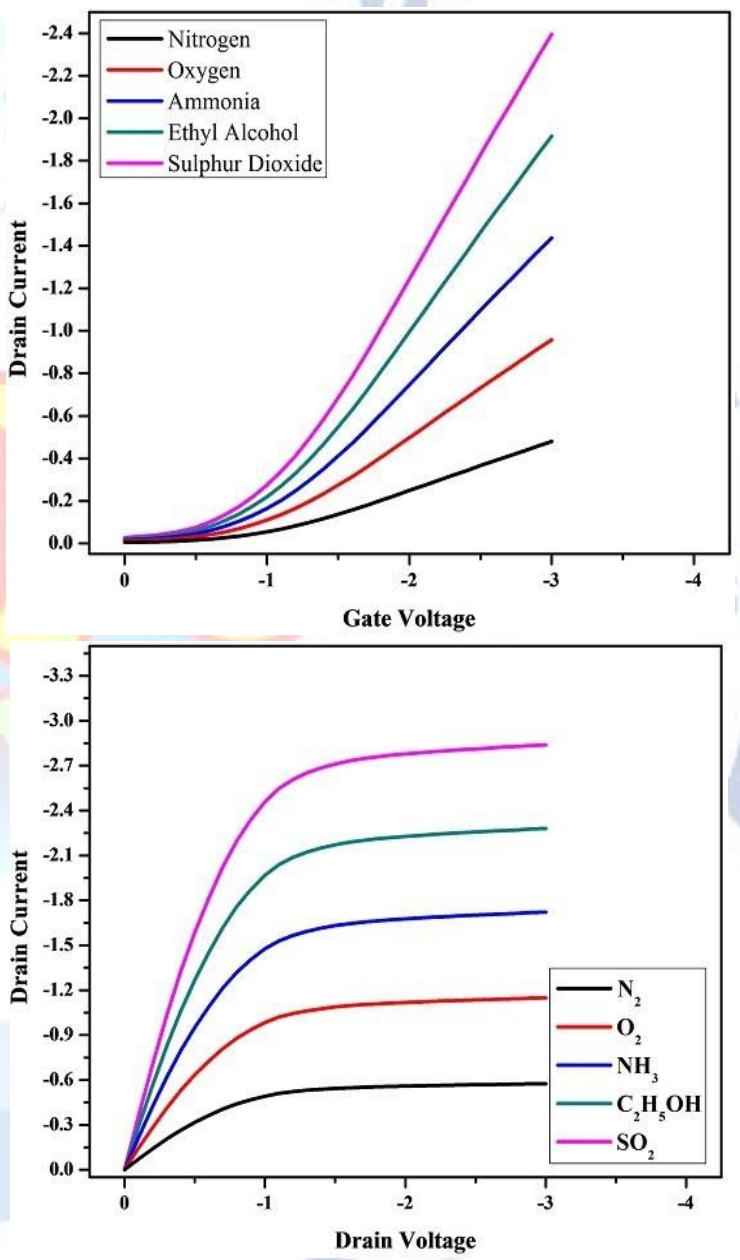

fig3-(a) Gate voltage against drain current

characteristic (b) Drain voltage gain stdrain current characteristic of sensor using $\mathrm{Al} 2 \mathrm{O} 3$ as adielectric

Case 2- Silicon dioxide as a dielectric

The device was analysedwith silicondioxide $\left(\mathrm{SiO}_{2}\right)$ as a dielectric material. Table 2 shows the deflection in min. and max. Drain current and Ion / Ioff ratio whereas Fig 4 depicts the graphical representation between the Gate voltage versus drain current as well as Drain 
voltage versus drain current characteristic of sensor. The sensitivity of the arrangement was calculated as 0.02964 .

\begin{tabular}{|c|c|c|c|c|}
\hline Gas & Permittivity & $\begin{array}{c}\text { Min. Drain } \\
\text { Current } \\
\left(\mathbf{I d}_{\text {nin }}\right)\end{array}$ & $\begin{array}{c}\text { Max. Drain } \\
\text { Current }_{\left(\mathbf{I d}_{\text {max }}\right)}\end{array}$ & Ion/ Ioff \\
\hline $\begin{array}{c}\text { Sulphur } \\
\text { Dioxide }\end{array}$ & 82 & 6.18635 & 5.84583 & 72.4916 \\
\hline $\begin{array}{c}\text { Ethyl } \\
\text { Alcohol }\end{array}$ & 78 & 6.17897 & 5.84574 & 72.5102 \\
\hline Ammonia & 71 & 6.16584 & 5.84559 & 72.5431 \\
\hline Oxygen & 4.94 & 6.0215 & 5.84413 & 72.8733 \\
\hline Nitrogen & 2.72 & 6.0156 & 5.84408 & 72.8894 \\
\hline
\end{tabular}

Table 2- Variation of min. and max. drain current and Ion/Ioff due to different gasses

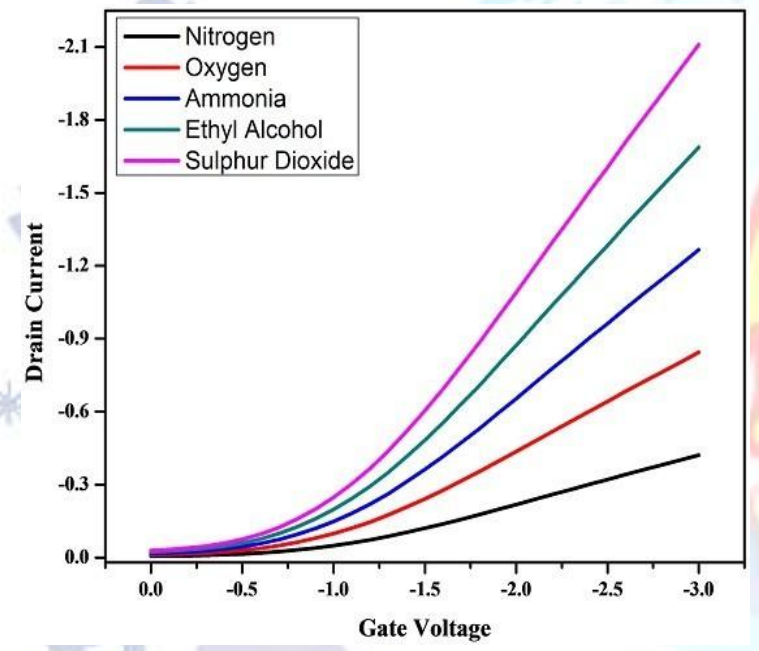

(a)

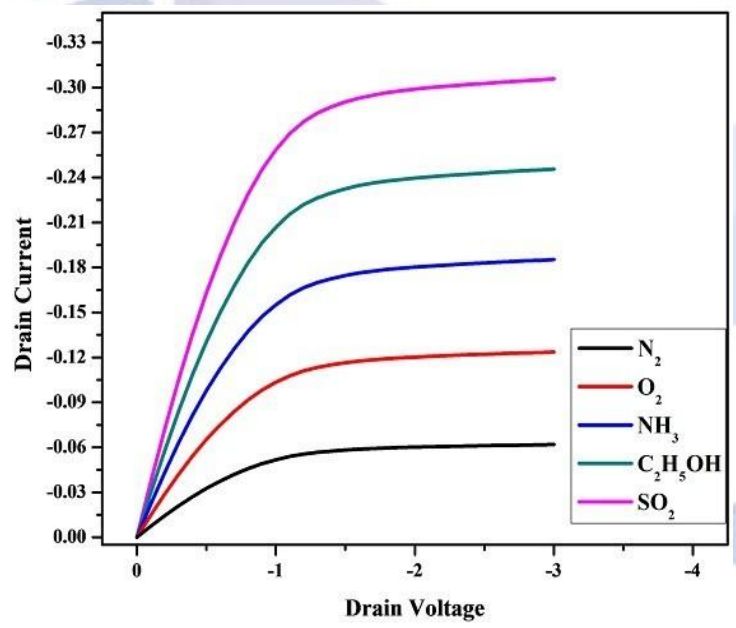

(b)

Fig3-(a) Gate voltage against drain current characteristic (b) Drain voltage against drain current characteristic of sensor using $\mathrm{SiO} 2$ as adielectric
Comparison in the absence of any toxicair was done and gate voltage against drain current characteristic and drainvoltage against drain current characteristic of sensor usingSiO $\mathrm{Si}_{2}$ and $\mathrm{Al}_{2} \mathrm{O}_{3}$ as a dielectric was analysed. Below Fig 4 depicts the comparison madeby graphically plotting Gate voltage against drain current characteristic and Drain voltage againstdrain current characteristic of sensor usingSiO ${ }_{2}$ and $\mathrm{Al}_{2} \mathrm{O}_{3}$ as a dielectric whereas Table 3 shows a numerical Comparison ofvariation between minimum and maximum Drain current and ratio of Ion/Ioffin absence of gas utilising $\mathrm{Al}_{2} \mathrm{O}_{3}$ and $\mathrm{SiO}_{2}$ as a dielectric material in thedevice.

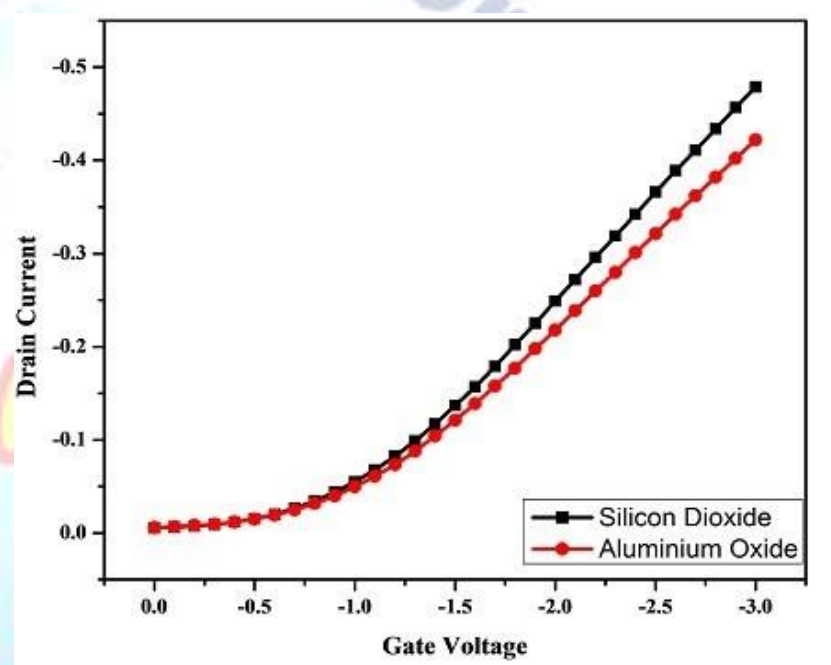

(a)

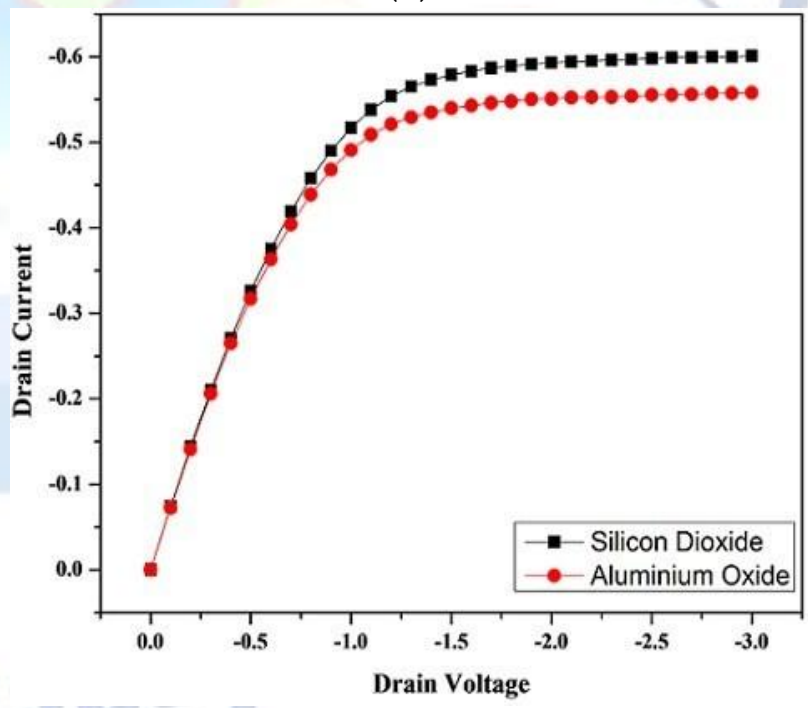

(b)

Fig4-(a)Gate voltage against drain current characteristic (b) Drain voltage against drain current characteristic of sensor using $\mathrm{SiO} 2$ and $\mathrm{A} 12 \mathrm{O} 3$ as a dielectric iscompared 


\begin{tabular}{|c|c|c|c|}
\hline Gas & $\begin{array}{c}\text { Min. Drain } \\
\text { Current Id }_{\min }\end{array}$ & $\begin{array}{c}\text { Max. Drain } \\
\text { Current Id }_{\max }\end{array}$ & Ion /Ioff \\
\hline No Gas & 5.57511 & 6.63199 & 88.6894 \\
\hline
\end{tabular}

(a)

\begin{tabular}{|c|c|c|c|}
\hline Gas & $\begin{array}{l}\text { Min. Drain } \\
\text { Current }\left(I_{\text {min }}\right)\end{array}$ & $\begin{array}{c}\text { Max. Drain } \\
\text { Current }\left(\text { Id }_{\text {max }}\right)\end{array}$ & Ion/Ioff \\
\hline No Air & 6.00822 & 5.84402 & 72.9043 \\
\hline
\end{tabular}

(b)

Table 3- Comparison of variation of min. and max. Drain current and Ion/Ioff due in absence of gas(a)Al2O3asdielectric (b)SiO2asdielectric

\section{CONCLUSION}

The organic thin film transistor based bottom gate bottom (BGBC) contact pentacene sensor served as an excellent gas sensor which was visualised through the simulation result in the form of variation between its max. and min. drain current and Ion / Ioff ratio. The Ion / Ioff ratio in the case of aluminium oxide was found to be greater as compared to silicon dioxide whereas the minimum drain current was greater in the case of silicon dioxide and vice versa for the maximum drain current. On comparing the sensitivity of the device, which is the ratio of difference between min. drain current in the presence of any toxic gas and min. drain current in the absence of air to the min. drain current in the absence of air with respect to the two different electrodes was found to be 0.0314 for aluminium oxide and 0.02964 for silicon dioxide. Hence, aluminiumoxide taking upper hand in sensitivity.

\section{REFERENCES}

[1] L.Gomes, E.Bentes, P.Stallingaand L.Moura, "Detection of explosive vapoursusing organic thin-film transistors, "ProceedingsofIEEESensor, 2004,Volume2 pp.766- 769

[2] Bo Liu , Xian Li , Guang-ZhongXie, Xiao-Song Du and Ping Sun, "Pentacenebased organic thin-film transistor as gas sensor,"Internationalconferenceonapperceivingcomp utingand intelligence analysis , 2009, pp.1-4.

[3] DrSubhadraRajpoot'Use Of Biofuels To Control Pollution In Automobiles" International Journal of Engineering Research and General Science Volume 4, Issue 4, July-August, 2016 ISSN 2091-2730.

[4] D. N. Lambeth and B. Li, "Nanostructure polymer transistorforvolatileorganiccompounddetection",Inter national

solidstatesensor,actuatorandmicrosystemconference, 2009,pp. 596-599.
[5] Dr.SubhadraRajpoot, Kabom Lego, Effect Of Particulate Matter (Pm) On Climate, Plants, Human Health And Ecosystem , International Journal Of Scientific Research : Volume-7 | Issue-5 | May-2018

[6] C.D.sheraw, "organicthin-filmtransistordrivenpolymer dispersed liquid crystal displays on flexible polymeric substrat e" , Appl. Physics Letter Vol. 80, pp 1088,2002.

[7] Dr. SubhadraRajpoot, "Renewableenergy And Its Future Potentialin India"”, International Journal for Modern Trends in Science and Technology, Vol. 05, Issue 05, May 2019, pp.-12-15.

[8] D.A.Ender,P.F.Baude,M.A.Haas, D.V.Muyres, T.W.Kelley, and S.D. Theiss, "Pentacenebased radio frequency

identificationcircuit”Appl.PhysicsLetterVol.82,pp 3964,2003.

[9] Dr. SubhadraRajpoot, "A Review on ways to Manage Biomedical Waste at Different Locations in Faizabad", International Journal for Modern Trends in Science and Technology, Vol. 06, Issue 01, January 2020, pp.-33-36..

[10] H. W. Zan, W. W. Tsai, Y. r. Lo, Y. M. Wu and Y. S. Yang,"Pentacene-BasedOrganicThinFilmTransistorsfor Ammonia

Sensing,"inIEEESensorsJournal,vol.12,no.3,pp.594-6 01, March 2012.

[11] C.M.J.Mutsaers, C.J.Drury,C.M.Hart,M.Matters,D.M.de Leeuw, "Lowcost all polymer integrated circuits" ,Appl. Physics Letter Vol 73, pp10-110,1998.

[12] Dr. SubhadraRajpoot and DevangPratap Singh, "Emerging Public Health Concern and Air Pollution: A Case Study of Delhi's Air Pollution Governance", International Journal for Modern Trends in Science and Technology, Vol. 06, Issue 05, May 2020, pp.: 196-201 